\title{
Itinerário de utentes com fibrose pulmonar idiopática atendidos via judicial ou administrativa pela Secretaria de Estado de Saúde do Pará
}

Itinerary of patients with idliopathic pulmonary fibrosis assisted by the judicial or administrative authorities of the State of Pará

Itinerario de usuarios con fibrosis pulmonar idiopática tratados judicial o administrativamente por el Departamento de Estado de Salud de Pará

\section{Resumo}

Objetivo: Investigar o itinerário de utentes que tiveram acesso aos medicamentos antifibróticos nintedanibe e pirfenidona via judicial ou administrativa; assim como, seus respectivos perfis socioeconômicos e epidemiológicos atendidos na Farmácia de Demandas Judiciais e Administrativas. Método: Trata-se de estudo transversal, retrospectivo, analítico-descritivo, qualitativo-quantitativo. Apresenta-se os dados socioeconômicos e demográficos do utentes. Resultados: Os achados nos informam que há prevalência de demanda via administrativa em relação a demanda via judicial. Os utentes têm dificuldade para efetuar o cadastro, renovação e o acesso ao medicamento; logo, apresentam dificuldades para adesão e continuidade ao tratamento. Conclusão: Infere-se que há dificuldades no acesso ao tratamento da FPI no Pará, sendo que a adesão ao tratamento e a continuidade estão prejudicadas pela inconstância na aquisição dos antifibróticos. Há prejuízos para a qualidade de vida dos utentes. Constatou-se altos gastos com a aquisição dos medicamentos antifibróticos.

Palavras-chave: Doenças raras; Fibrose Pulmonar Idiopática; Assistência farmacêutica; Cuidado farmacêutico; Medicamentos.

\footnotetext{
Abstract

Objective: To investigate the itinerary of users who had access to the antifibrotic drugs nintedanib and pirfenidone via judicial or administrative procedures; as well as their respective socioeconomic and epidemiological profiles served by the Judicial and Administrative Demands Pharmacy. Method: This is a cross-sectional, retrospective, analyticaldescriptive, qualitative-quantitative study. The socioeconomic and demographic data of the users are presented. Results: The findings inform us that there is a prevalence of demand through the administrative process in relation to the demand through the courts. Users find it difficult to register, renew and access the medicine; therefore, they present difficulties for adherence and continuity of treatment. Conclusion: It is inferred that there are difficulties in accessing treatment for IPF in Pará, and treatment adherence and continuity are hampered by the inconstancy in the acquisition of antifibrotics. There is damage to the quality of life of users. There were high expenses with the acquisition of antifibrotic drugs.
} 
Keywords: Rare diseases; Idiopathic Pulmonary Fibrosis; Pharmaceutical assistance; Pharmaceutical care; Medicines.

\section{Resumen}

Objetivo: investigar el itinerario de los usuarios que tuvieron acceso a los fármacos antifibróticos nintedanib y pirfenidona a través de procedimientos judiciales o administrativos; así como sus respectivos perfiles socioeconómicos y epidemiológicos atendidos por la Farmacia de Demandas Judiciales y Administrativas. Método: Se trata de un estudio transversal, retrospectivo, analítico-descriptivo, cualitativo-cuantitativo. Se presentan los datos socioeconómicos y demográficos de los usuarios. Resultados: Los hallazgos nos informan que existe un predominio de la demanda a través del proceso administrativo en relación a la demanda a través de los tribunales. Los usuarios tienen dificultades para registrarse, renovar y acceder al medicamento; por tanto, presentan dificultades para la adherencia y continuidad del tratamiento. Conclusión: Se infiere que existen dificultades para acceder al tratamiento de la FPI en Pará, y la adherencia y continuidad del tratamiento se ven obstaculizadas por la inconstancia en la adquisición de antifibróticos. Hay daños en la calidad de vida de los usuarios. Hubo altos gastos con la adquisición de fármacos antifibróticos.

Palabras clave: Enfermedades raras; Fibrosis Pulmonar Idiopática; Asistencia farmacéutica; Atención farmacéutica; Medicinas.

\section{Introdução}

A fibrose pulmonar idiopática é definida como uma forma específica de pneumonia intersticial fibrosante crônica, limitada ao pulmão e associada com padrão histológico de pneumonia intersticial usual em biópsia cirúrgica do pulmão. Sua etiologia é desconhecida. Nos estágios iniciais da fibrose pulmonar idiopática, a função pulmonar ou os achados pulmonares de imagem podem ser normais ou apenas ligeiramente comprometidos. Pacientes com histórico de tabagismo podem ter doença pulmonar obstrutiva crônica coexistente, o que irá alterar as manifestações da doença, avaliada pela função pulmonar e exames de imagem de tórax (American Thoracic Society, 2000).

O diagnóstico de fibrose pulmonar idiopática é baseado na ausência de uma causa conhecida de fibrose pulmonar associada à presença de padrão pneumonia intersticial usual. Esse é o aspecto chave no processo de diagnóstico. Anos atrás o tratamento da doença ainda se constituía como uma incógnita, pois não havia fármacos específicos para tratá-la, sendo assim, eram utilizadas diversas classes terapêuticas, especialmente os glicocorticoides, que foram amplamente utilizados, porém não resultavam em regressão da condição clínica dos pacientes (Swigris \& Brown, 2006 ).

No Brasil, ainda não se tem dados específicos e confiáveis sobre a ocorrência da fibrose pulmonar idiopática e, estabelecer a epidemiologia da doença ainda é um grande desafio a ser vencido. Não se tem dados concretos sobre quantos pacientes são diagnosticados com fibrose pulmonar idiopática por ano no país. Esse fato afeta, em especial, decisões governamentais ligadas à saúde, pois estas devem basear-se em dados epidemiológicos robustos, os quais, infelizmente, em relação à fibrose pulmonar idiopática, são escassos no Brasil (Baddini-Martinez et al., 2015).

Tomando como base dados do recenseamento populacional de 2010 do IBGE e em alguns índices levantados por um estudo realizado nos EUA, seriam esperados, no ano de 2010, 923 casos novos de fibrose pulmonar idiopática, e a mortalidade atribuível à doença seria de 2.310 óbitos. Porém, tais números soam excessivamente baixos e, sem dúvida, refletem não apenas subnotificação, como também desconhecimento e falta de diagnóstico da doença (Instituto Brasileiro de Geografia e Estatística, 2010; Rufino et al., 2013; Baddini-Martinez et al., 2015).

Os dados epidemiológicos apresentados são baseados em estudos realizados nos EUA, devido este país possuir características migratórias semelhantes às brasileiras. Através destes estudos, pôde-se supor que, no Brasil, a incidência anual de casos de fibrose pulmonar idiopática gira entre 6.841 e 9.997 casos (3,5 a 5,1 por 100.000 habitantes) e que a prevalência possa variar entre 13.945 e 18,305 casos (7,1 a 9,4 por 100.000 habitantes). A fibrose pulmonar idiopática raramente ocorre em 
jovens, o que altera a sua possível prevalência. Então, quando a análise se limita apenas a faixas etárias a partir dos 55 anos, a prevalência projetada gira entre 9.986 e 16.109 casos (5,1 a 8,3 por 100.000 habitantes) (Robalo Cordeiro et al., 2016).

De acordo com Robalo Cordeiro et al. (2016), a fibrose pulmonar idiopática afeta principalmente pessoas com 50 ou mais anos de idade. Aproximadamente dois terços das pessoas diagnosticadas com a doença têm 60 ou mais anos de idade à época do diagnóstico. Talvez, por este motivo, a fibrose pulmonar idiopática seja relacionada à menor sensação de bem-estar dos pacientes. A doença limita a capacidade de realizar tarefas diárias por facilitar a ocorrência de fadiga, cansaço, falta de ar e também restringe a realização de exercícios físicos, pois deve-se evitar que os pacientes sobrecarreguem sua função respiratória. Esta condição também pode contribuir para o sedentarismo e ocasionar ganho de peso, afetando a autoestima dos portadores de fibrose pulmonar idiopática (Baddini-Martinez et al., 2015).

Além da falta de conhecimento da equipe multiprofissional sobre a doença, da subnotificação e consequente falha nos dados epidemiológicos, outra barreira a ser quebrada para os pacientes com fibrose pulmonar idiopática é o tratamento. Tratar estas pessoas sempre foi um grande desafio, mas, no final de 2014, duas novas drogas foram aprovadas pela Food and Drug Administration (FDA) para o tratamento desses pacientes nos EUA. Estudos atestam que ambas as drogas reduzem o ritmo de queda da função pulmonar dos acometidos pela doença. No entanto, outros ensaios clínicos estão em andamento investigando novos fármacos com mecanismo de ação diverso (Baddini-Martinez et al., 2015).

O tratamento para a fibrose pulmonar idiopática é crônico e conforme a descrição na bula do fabricante, consiste em iniciar com 1 comprimido 3 vezes ao dia durante 7 dias; após a primeira semana, deve-se aumentar a dose para 2 comprimidos 3 vezes ao dia por mais 7 dias, e, ao chegar na terceira semana, o paciente deverá tomar 3 comprimidos 3 vezes ao dia, totalizando 270 comprimidos por mês, quando se trata do medicamento antifibrótico Pirfenidona Para o Nintedanibe, o tratamento consiste em 60 cápsulas por mês, tomando-se duas ao dia.

Kaminosono, Gomes e Soler (2020), ao analisarem a percepção de idosos com Fibrose Pulmonar Idiopática sobre a qualidade de vida, constataram que $80 \%$ dos participantes são idosos do sexo masculino e a idade média foi de 74 anos. A pontuação no World Health Organization Quality of Life-Bref (WHOQOL-Bref), dos escores para tais domínios, respectivamente: físico=64,29, psicológico=73,21, social=84,52 e ambiental=74,55 e, concluíram que os utentes apresentam boa qualidade de vida. O instrumento utilizado mostrou-se sensível ao objetivo pretendido, permitindo verificar consonância com outros estudos em relação às facetas que mais influenciam a qualidade de vida desta população.

Como no Brasil ainda não há um Protocolo Clínico e Diretrizes Terapêuticas (PCDT) para a fibrose pulmonar idiopática e a Comissão Nacional de Incorporação de Tecnologias (CONITEC) no Sistema Único de Saúde (SUS) não concedeu parecer favorável à incorporação dos medicamentos no sistema de saúde brasileiro (Brasil, 2015), os medicamentos disponíveis para o tratamento da doença, Ofev ${ }^{\circledR}$ (nintedanibe) e Esbriet ${ }^{\circledR}$ (pirfenidona), só podem ser entregues aos pacientes através de demanda administrativa - via solicitação para a secretaria de saúde do estado -, ou por via judicial; visto que, estas alternativas terapêuticas são de alto custo e a compra dos medicamentos para o tratamento da doença se torna inviável para os pacientes custearem.

\subsection{Doenças raras no Brasil}

No Brasil, a regulamentação das políticas para portadores de doenças raras é baseada na Portaria GM/MS n 199 , de 30 de janeiro de 2014, que institui a Política Nacional de Atenção Integral às Pessoas com Doenças Raras, aprova as Diretrizes para Atenção Integral às Pessoas com Doenças Raras no âmbito do Sistema Único de Saúde (SUS) e institui incentivos financeiros de custeio. 
A referida portaria estabelece em seu art. $4^{\circ}$ que o governo se compromete em promover ações para que se possa “reduzir a mortalidade, contribuir para a redução da morbimortalidade e das manifestações secundárias e a melhoria da qualidade de vida das pessoas, por meio de ações de promoção, prevenção, detecção precoce, tratamento oportuno redução de incapacidade e cuidados paliativos" (BRASIL, 2014).

De acordo com Morais (2019), um dos consensos para diagnóstico, preconiza que os critérios para suspeitar de fibrose pulmonar idiopática são: dispneia, idade acima de 50 anos, ser ou ter sido fumante, tosse não produtiva, crepitações na ausculta e hipocratismo digital. Para confirmar o diagnóstico é necessário realizar uma Tomografia Computadorizada de Alta Resolução (TCAR), onde será pesquisado o padrão de Pneumonia Intersticial Usual. Ainda é possível realizar exames laboratoriais ou exames para biomarcadores, para casos em que há suspeita de outra doença. Portanto, quando há dúvidas quanto ao diagnóstico, devem ser excluídas as possíveis causas, que incluem outros tipos de pneumonias intersticiais, um grupo amplo no qual a fibrose pulmonar idiopática está incluída.

\subsection{Diagnosticando a fibrose pulmonar idiopática}

A fibrose pulmonar idiopática ainda consiste em um desafio até para os profissionais especialistas em doenças pulmonares. Ela faz parte das doenças pulmonares intersticiais e está entre as com a ocorrência mais comum, apesar de ser rara (Richeldi et al., 2019). Seu diagnóstico ainda é difícil, mesmo com os notáveis avanços nos últimos anos. Ainda é necessário estabelecer e aprimorar critérios precisos para identificá-la (American Thoracic Society, 2000; Baddini-Martinez et al., 2015).

Para um diagnóstico correto da doença, estão envolvidos diversos profissionais como pneumologistas, radiologistas e patologistas. A avaliação inicial deve incluir história e exame físico completos, seguidos de testes laboratoriais e de imagem: testes hematológicos de rotina, radiografia de tórax, tomografia computadorizada de alta resolução da região torácica, gasometria arterial e testes de função pulmonar, incluindo DLCO e medida da SpO2 no esforço (Richeldi et al., 2018).

Além destes exames, alguns fatores externos também estão relacionados com o aparecimento da doença, eles podem ser tabagismo, doença do refluxo gastroesofágico (DRGE), histórico familiar, história ocupacional e uso de medicações, Richeldi et al., (2018) citam principalmente os antineoplásicos e reforçam que o aparecimento da lesão independe da dose e do tempo de exposição. Por outro lado, a Sociedade Brasileira de Pneumologia e Tisiologia aponta que o uso de antidepressivos também pode desencadear a fibrose pulmonar idiopática, sendo a significância deste dado desconhecida (SOCIEDADE BRASILEIRA DE PNEUMOLOGIA E TISIOLOGIA, 2012).

\subsection{Tratamento da fibrose pulmonar idiopática}

A terapia de escolha para os pacientes com fibrose pulmonar idiopática consistia em administrar medicamentos antiinflamatórios, os corticosteroides, principalmente. No entanto, nestes pacientes se observava pouca ou nenhuma inflamação, o que tornava essa opção terapêutica ineficaz e reforçava a importância de fármacos específicos para esta condição. Além da terapia com anti-inflamatórios esteroides, também são/eram utilizados citotóxicos como ciclofosfamida, imunossupressores como azatioprina e antifibróticos como interferon $\beta$ e interferon $\gamma$ (SOCIEDADE BRASILEIRA DE PNEUMOLOGIA E TISIOLOGIA, 2012).

Em sua visita inicial ao pneumologista $57 \%$ dos pacientes com fibrose pulmonar idiopática reportaram terem sido alertados de que a doença é progressiva; entretanto, mesmo com o mau prognóstico (2 a 5 anos após o diagnóstico confirmado), menos da metade se recordam de serem informados sobre opções de tratamento. Também, de acordo com a Sociedade Brasileira de Pneumologia e Tisiologia, os especialistas que demoraram mais de 4 meses para iniciar o tratamento de seus pacientes se sentiram desconfortáveis ao discutirem o prognóstico com eles e tinham menos esperança na eficácia dos 
agentes antifibróticos do que os especialistas que iniciaram a terapia medicamentosa dentro de 4 meses (SOCIEDADE BRASILEIRA DE PNEUMOLOGIA E TISIOLOGIA, 2012).

Esse dado é importante para se discutir a necessidade de educar continuamente os médicos (mesmo que especialistas em pneumologia) para que se tenha o melhor manejo possível com os pacientes diagnosticados com fibrose pulmonar idiopática, não só por ser uma doença rara, mas por ter um prognóstico ruim, opções terapêuticas com benefícios controversos, que requerem uso crônico e que tem possíveis efeitos adversos desconfortáveis, sendo assim, é imprescindível que o paciente receba toda a orientação e cuidado necessários para lidar com seu diagnóstico.

\subsection{As novas opções terapêuticas para tratar a fibrose pulmonar idiopática}

Recentemente, foram lançados dois antifibróticos que prometem diminuir a capacidade de progressão da fibrose pulmonar idiopática, estes são nintedanibe (Ofev®) e pirfenidona (Esbriet®). As duas alternativas terapêuticas foram aprovadas pela ANVISA, no Brasil e em diversos países Europeus, assim como no Canadá, Estados Unidos e Japão. De acordo com a autorização em bula disponibilizada pelo fabricante Bohringer Ingelheim, o nintedanibe é um inibidor do processo de proliferação, migração e transformação de fibroblastos, que são células envolvidas no aparecimento da fibrose pulmonar idiopática, logo, possui a capacidade de tratar e diminuir a progressão da doença.

Consta na bula profissional de pirfenidona, disponibilizada pela fabricante Roche, o mecanismo de ação deste fármaco ainda não foi completamente estabelecido. No entanto, os estudos disponíveis indicam que a pirfenidona exerce tanto propriedades antifibróticas quanto anti-inflamatórias. A pirfenidona demonstrou-se capaz de minimizar o acúmulo de células inflamatórias frente à diferentes estímulos, o que é útil no tratamento da fibrose pulmonar idiopática. A bula destaca ainda que o medicamento atenua a proliferação de fibroblastos, produção de proteínas associadas à fibrose e citocinas e o aumento de biossíntese e acúmulo de matriz extracelular.

Quanto à dados que comprovem a sua segurança e eficácia, Rogliani et al., (2016) confirmam que tanto a pirfenidona quanto o nintedanibe reduzem a progressão da fibrose pulmonar idiopática com um perfil de segurança semelhante, embora o nintedanibe pareça ser mais efetivo na redução do risco de exacerbações e taxa de mortalidade. Ren et al., (2017) e Rogliani et al., (2016) demostraram que a pirfenidona pode reduzir a progressão da doença, avaliada pelo declínio da Capacidade Vital Forçada (CVF).

Maher e Strek (2019) demonstram que apesar de serem associados à efeitos adversos cutâneos (fotossensibilidade, rash cutâneo) e gastrointestinais (diarreia e perda de apetite), estes não são classificados como graves e não devem ser um empecilho para iniciar a farmacoterapia. A pirfenidona diminui a progressão da doença e a mortalidade na fibrose pulmonar idiopática; o nintedanibe consegue diminuir o declínio da função pulmonar.

Naqvi et al., (2019) investigaram durante 24 meses o tratamento com antifibróticos em pacientes diagnosticados com fibrose pulmonar idiopática e a descontinuidade do tratamento devido aos efeitos adversos destes. Dos 106 pacientes que recebiam nintedanibe, $47 \%$ precisaram reduzir a dose prescrita ou descontinuaram a terapia. 40 pacientes recebiam pirfenidona e destes, $43 \%$ precisaram reduzir a dose ou abandonaram o tratamento. Os autores destacam que o motivo mais frequente para o abandono do tratamento com ambos antifibróticos foram os efeitos adversos, que afetavam a qualidade de vida dos pacientes; já $5 \%$ dos pacientes em uso de nintedanibe interromperam o uso por efeitos cardiovasculares.

Em uma metanálise realizada por Loveman et al., (2015) foi feita uma comparação indireta entre os dois antifibróticos, que indicou que o nintedanibe obteve significância estatística maior que pirfenidona em desacelerar o declínio da capacidade vital forçada. Em comparação de mortalidade, os resultados não foram estatisticamente significantes entre as duas opções terapêuticas. 
Quando se trata de custo-efetividade, na análise de Ho et al., (2017) a pirfenidona se sobressaiu em relação ao nintedanibe em todos os desfechos, mostrando melhores resultados em parâmetros essenciais para se medir a progressão da doença, sendo um indicador do sucesso terapêutico, que são: anos de vida ajustados pela qualidade (Quality Ajusted Life Years) de 0.47, de anos de vida (Life Years) de 0.81 e 0.40 de ganho de sobrevida livre de progressão (Progress Free Survival), quando comparado ao nintedanibe. Os autores concluíram que a pirfenidona se mostrou dominante e tem potencial de reduzir os custos associados ao tratamento da fibrose pulmonar idiopática, quando comparado à opção nintedanibe.

Kaminosono et al., (2020), ao sintetizarem evidências científicas sobre a efetividade, segurança e eficiência do uso do nintedanib e da pirfenidona me pacientes com Fibrose Pulmonar Idiopática (FPI), concluíram que a pirfenidona apresenta eficácia no risco de morte por todas as causas, bem como no risco de morte por FPI em 1 ano, sendo capaz de reduzir o risco de agravamento do quadro de dispneia, em comparação com placebo. No que tange ao nintedanib os estudos demonstram retardo na progressão da FPI quando comparado ao placebo e redução significativa no risco de exacerbações agudas. Ambas as drogas parecem ser bem toleradas.

\subsection{Judicialização do acesso aos medicamentos para fibrose pulmonar idiopática}

Mesmo com os avanços das políticas públicas da Assistência Farmacêutica ainda há barreiras que bloqueiam o acesso da população aos medicamentos, isso implica no aumento do número de ações judiciais movidas por pacientes, a lenta obtenção de novas tecnologias tem propiciado um aumento frequente dos gastos do Estado isso contribui para uma perda crescente da economia do país, a urgência de compras de medicamentos individualizadas leva a uma aquisição mais cara, os gastos com as tecnologias não correspondem a evolução significativa nos índices de saúde, e o acesso a farmacoterapia não acomoda toda a população apenas uma pequena parcela é beneficiada com os recursos terapêuticos ofertados (Vieira \& Zucchi, 2013). Conforme Mota et al. (2003) "No Brasil, o volume de recursos financeiros da esfera federal investido na compra e distribuição gratuita de medicamentos no Sistema Único de Saúde (SUS) representou, em 2002, 9,7\% do gasto em saúde financiado pelo Ministério da Saúde". Neste sentido quando se fala em direito à saúde, leva-se em conta as leis nacionais garantindo o direito fundamental dos cidadãos, no Brasil as ações governamentais dão suporte ao SUS, que reconhece a promoção, proteção e a recuperação da saúde como direito fundamental da população, entretanto quando os usuários julgam que seus direitos foram violados, entram com ações judiciais, reivindicando o acesso aos medicamentos (Cannon, 2012). Tratar sobre o assunto em questão é de fundamental importância, visto que o impacto financeiro com ações de cunho jurídicas tem se tornado um forte fenômeno na concretização dos direitos da população, não obstante os gastos do ministério da saúde com a obtenção dos medicamentos tem propiciado um forte comprometimento nos cofres públicos.

As reivindicações para o acesso aos medicamentos nintedanibe e pirfenidona fundamentam-se no direito à saúde garantido pela constituição federal, isso resulta no dever estatal de prestar assistência à saúde individual, de forma integral, universal e gratuita, seguindo os princípios e diretrizes do Sistema Único de Saúde (SUS) brasileiro (Ventura et al., 2010).

Catanheide et al., (2016) analisaram 53 trabalhos que abordaram o acesso à medicamentos através da judicialização. De acordo com os autores, em quase todos os casos o parecer é favorável e as liminares são concedidas, mas destaca que parcela considerável das ações poderia ter sido evitada caso fossem observadas as alternativas terapêuticas do SUS.

Brandão et al., (2021), ao estudar o "Cumprimento do protocolo clínico para atendimento de usuários de análogos de insulina em portadores de Diabetes Mellitus via judicial em Belém, Pará”, propõem que haja uma reflexão sobre a importância não só da acessibilidade aos medicamentos via judicial; mas, imprescindivelmente da qualidade do acesso aos serviços de cuidados ofertados. 
Assim, o acesso aos fármacos antifibróticos ainda é limitado. Frente a isso, questiona-se o papel do Estado em fornecer medicamentos caros a estes pacientes, que depositam sua esperança no tratamento farmacológico. Apesar de haver opções terapêuticas para tratar a fibrose pulmonar idiopática, ter acesso a elas torna-se uma dificuldade, que é causada pela baixa prevalência dessa doença, associada ao alto custo dos tratamentos inovadores não incluídos no Sistema Único de Saúde (pirfenidona e nintedanibe) e isso faz com que tanto a noção de integralidade de atendimento quanto a de universalidade do SUS sejam colocadas em xeque (Ventura et al., 2010).

O caminho mais escolhido pelos pacientes que são diagnosticados com fibrose pulmonar idiopática é a abertura de processos administrativos ou judiciais para que o governo disponibilize o tratamento. Este fenômeno ficou conhecido como “judicialização da saúde” e está ocorrendo em escala crescente no Brasil, devido ao fato de que muitas opções de tratamento para as mais diversas doenças foram (ou não) aprovadas pela ANVISA e, não estão inseridas nos Componentes da Assistência Farmacêutica do SUS nem em Protocolos Clínicos e Diretrizes Terapêuticas; logo, o orçamento destinado à aquisição de medicamentos que fazem parte dos blocos de financiamento da Assistência Farmacêutica não prevê a sua aquisição.

Por outro lado, esta prática causa grande impacto ao orçamento público e ao mesmo tempo demonstra a desigualdade entre os que têm condições de contratar advogados e arcar com os custos de um processo; e os que não têm condição e tampouco conhecimento sobre os procedimentos legais que, nestes casos, garantem o acesso ao tratamento.

Outro ponto que a judicialização da saúde traz à tona é a demora da incorporação de novas tecnologias ao sistema de saúde pela Comissão de Incorporação de Tecnologias (CONITEC), que é regulada pela Lei 12.401, de 28 de abril de 2011 . No caso do tratamento da FPI, os ensaios clínicos disponíveis, como o ensaio clínico de fase III iniciado para investigar o efeito de Pirfenidona na capacidade de força vital, nomeado ASCEND; e o ensaio clínico de fase III nomeado INPULSIS demonstraram a segurança e efetividade de nintedanibe e pirfenidona no tratamento da doença. Mas, apesar destes dados, ainda são necessários mais estudos para corroborar sua tolerância à longo prazo.

Os medicamentos nintedanibe e pirfenidona foram aprovados pela Agência Nacional de Vigilância Sanitária (ANVISA) conforme RDC/ANVISA nº 1.548, de 10 de junho de 2016 e RDC/ANVISA n 2.958 , de 23 de outubro de 2015 , respectivamente. Desde então, os fármacos não foram incorporados à Protocolos Clínicos e Diretrizes Terapêuticas e, por consequência, não constam na lista do Componente Especializado da Assistência Farmacêutica (CEAF), o que não torna a sua aquisição obrigatória pelo SUS. Ela passa a ter caráter obrigatório em casos em que a compra seja exigida por ordem da justiça ou autorizada pela secretaria de estado de saúde. A incorporação de um destes medicamentos, o Ofev ${ }^{\circledR}$ (nintedanibe) um dos dois fármacos disponíveis para o tratamento da FPI no Brasil, passou por avaliação pela CONITEC no relatório de recomendação ${ }^{\circ} 419$ de 2018.

A Comissão de Incorporação de Tecnologias, deliberou e decidiu, em sua $67^{a}$ reunião ordinária, realizada no ano de 2018, pela não incorporação no SUS do esilato de nintedanibe para fibrose pulmonar idiopática. A comissão argumentou que os dados sobre sua eficácia e melhora na qualidade de vida e sobrevida a longo prazo são incertos, além disso, afirmou-se que os custos com a aquisição são muito elevados, considerando que há outras alternativas - como melhores cuidados de suporte que podem ser indicadas aos pacientes.

Em sua 72a reunião ordinária, realizada no dia 04 de outubro de 2018, a CONITEC reuniu-se para deliberar acerca da incorporação da pirfenidona ao SUS. O que a Comissão recomendou, preliminarmente, foi pela não incorporação da pirfenidona para fibrose pulmonar idiopática no SUS, considerando que embora os estudos indiquem benefícios do medicamento em relação ao declínio da capacidade vital forçada - CVF - (que mede o volume de ar exalado com esforço máximo) predita frente ao placebo, nem evidências que comprovem sua capacidade de diminuir casos de exacerbação aguda da 
doença, tampouco capacidade de diminuir as hospitalizações relacionadas à fibrose pulmonar idiopática. Quanto ao impacto orçamentário, foi ponderado e decidiu-se que havia elevada incerteza quanto as estimativas reais de custo-efetividade.

\subsection{O acesso à medicamentos para fibrose pulmonar idiopática no Pará}

Considerando que os medicamentos aprovados pela ANVISA para o tratamento da fibrose pulmonar idiopática não foram incorporados ao SUS, e que não há outras alternativas terapêuticas para essa patologia na Relação Nacional de Medicamentos Essenciais (RENAME), os pacientes podem solicitar que seu direito ao tratamento seja atendido por via judicial, através de um mandado do Tribunal de Justiça; ou administrativamente, por solicitação ao Secretário de Estado de Saúde, em atendimento à Instrução Normativa no 01 de 09 de março de 2017, que dispõe sobre o processo de obtenção de medicamentos no âmbito da Secretaria de Estado de Saúde do Pará (SESPA).

Para que um processo analisado obtenha aprovação para aquisição do medicamento, nele devem constar informações descriminadas na Instrução Normativa 01/17 (prescrição médica, laudo médico confirmando diagnóstico, relatório médico detalhado; artigos contendo evidências científicas que comprovem que o medicamento é eficaz para o tratamento), além de dados complementares como número do protocolo, requerimento endereçado à assessoria especial do gabinete da Secretaria de Estado de Saúde do Pará (SESPA), carteira de identidade, comprovante de residência, CPF, cartão SUS, ficha social (caso o paciente solicite a medicação por demanda administrativa), encaminhamento à SESPA, informações adicionais sobre o paciente, informações sobre a patologia, custos de tratamento, e o encaminhamento ao secretário adjunto de políticas de saúde. E, por fim, em caso de deferimento anexar, também, o autorizo do gestor.

Se tudo está em conformidade, o processo então segue para o Departamento de Assistência Farmacêutica (DEAF) para procedimento da aquisição, esta etapa pode ser demorada, tendo em vista que os 2 medicamentos disponíveis para o tratamento da fibrose pulmonar idiopática não são incluídos no SUS, Relação Nacional de Medicamentos Essenciais (RENAME), e tampouco na Portaria $n^{\circ}$ 1.554, de 30 de julho de 2013, que trata do Componente Especializado da Assistência Farmacêutica, e precisa-se realizar a compra através de processo licitatório, para cada demanda individualizada. Quando o medicamento está disponível no estoque da farmácia, o paciente é encaminhado para recebê-lo na Unidade de Referência Especializada Doca (URES/Doca), porém, quando não há estoque, é necessário aguardar o processo de aquisição, o que pode demorar meses.

Via de regra, os pacientes recebem o medicamento para 30 dias (mas também podem receber para períodos prolongados) e devem retornar mensalmente para recebê-lo, caso não recebam o tratamento para mais de 1 mês. Além disso, a cada 6 meses deve-se renovar a solicitação para continuar recebendo a medicação. Se o paciente deixar de comparecer à farmácia por mais do que 3 meses consecutivos, ele não terá o direito de receber o medicamento até que regularize o seu cadastro.

A Farmácia de Demandas Judiciais e Administrativas recebe os processos administrativos e judiciais após a tramitação destes pelos setores da Assessoria Especial, Departamento de Assistência Farmacêutica (DEAF), Setor de Compras, além do Gabinete da Secretaria de Estado de Saúde do Pará (SESPA), que realizam o processamento e análise de cada um para determinar se todos os critérios diagnósticos constam no processo e se o paciente anexou ao seu processo todos os documentos necessários para este ser aceito. Esta análise determina se o Estado pode fornecer o medicamento ao paciente solicitante, mediante o cumprimento dos requisitos legais.

Cabe ao gestor possibilitar o acesso ao tratamento e cabe ao paciente entender como ele pode garantir o cumprimento de seus direitos. Para que isso aconteça, é vital que toda e cada etapa deste processo, que é complexo, seja clara e esclarecida para os envolvidos, sendo esta falta de esclarecimento uma problemática encontrada ao decorrer da realização deste trabalho. 
Neste contexto, o objetivo do trabalho foi investigar o itinerário de utentes que tiveram acesso aos medicamentos antifibróticos nintedanibe e pirfenidona via judicial ou administrativo atendidos na farmácia de demandas judiciais e administrativas; assim como, seus respectivos perfis socioeconômicos, a origem da demanda e os custos envolvidos para o acesso ao tratamento da fibrose pulmonar idiopática no serviço público, o tempo de espera no decorrer do processo desde a solicitação inicial ao tratamento até a efetiva dispensação e as dificuldades na solicitação de renovação/continuidade do tratamento.

\section{Metodologia}

\subsection{Tipo e local do estudo}

Trata-se de um estudo transversal, retrospectivo, analítico-descritivo, qualitativo-quantitativo (Minayo, 2012; Yin, 2015). O local do estudo foi a "Farmácia de Demandas Judiciais e Administrativas" do Departamento Estadual de Assistência Farmacêutica (DEAF) da Secretaria de Estado de Saúde do Pará (SESPA), a qual ocupa um espaço na Unidade de Referência Especializada URE-DOCA, localizada na Av. Visconde de Souza Franco, s/n. Reduto, Belém. PA. CEP: 666053-0000. Fone: (91) 3204-3707. CNPJ SESPA: 05.054.929.0001-17.

\subsection{Critério de inclusão}

Processos de solicitação de utentes que receberam e/ou recebem os medicamentos para fibrose pulmonar idiopática via Secretaria Estadual de Saúde, a partir de demanda judicial e administrativa e que estejam cadastrados e sob supervisão da “Farmácia de Demandas Judiciais e Administrativas” do Departamento Estadual de Assistência Farmacêutica (DEAF/SESPA), no período de novembro de 2016 a dezembro de 2019.

\subsection{Universo do estudo}

A "Farmácia de Demandas Judiciais e Administrativas" do Departamento Estadual de Assistência Farmacêutica (DEAF) da Secretaria de Estado de Saúde do Pará (SESPA). Trata- se de uma farmácia onde são feitas as dispensações de medicamentos e materiais técnicos sob demanda judicial e administrativa, tendo controle informatizado. Trabalham nesta farmácia de demanda 01 farmacêutico, 01 agente administrativo e 01 funcionário terceirizada da UniHealth. O horário de funcionamento é de segunda-feira a sexta-feira das 08:00 as 15:00 horas.

\subsection{Amostra, coleta de dados e informações}

Utilizou-se de amostra por conveniência/consecutiva (Minayo, 2012; Yin, 2015) na qual coletou-se e categorizou-se todos os atendimentos e processos arquivados na farmácia. Foram analisados 81 processos de pacientes, sendo 57 de demanda administrativa e 24 de demanda judicial. A identificação do perfil socioeconômico e epidemiológico de utentes com fibrose pulmonar idiopática, foi realizada mediante a análise das informações documentais contidas nas fichas sociais que se encontra anexada ao processo de solicitação de cada paciente proveniente de demanda via administrativa. A ficha social faz parte de processo de origem para entrada de pedido de medicamentos via administrativa e é preenchida pela assistente social da SESPA que registra toda a informações através de entrevista com paciente ou responsável no ato da solicitação via administrativa.

As fichas sociais dos pacientes contêm dados referentes ao nome completo, data de nascimento, idade, gênero, município, origem do atendimento (público ou privado), profissão, moradia (própria, alugada ou cedida), tipo de moradia (alvenaria ou madeira), número de moradores na casa e situação socioeconômica (renda líquida total). Os pacientes que são 
provenientes de demanda via judicial não possuem a ficha social anexada em seu processo, pois a origem não se dá na Secretaria de Estado e sim no Tribunal de Justiça, logo, não há meios para que seja realizada a coleta de dados relacionados ao perfil socioeconômico e epidemiológico dos mesmos.

Para a coleta de dados referente aos custos com a aquisição e dispensação, estes foram extraídos das Notas de Empenho e Notas Fiscais de compras e relatório de atendimento, por meio físico ou do Sistema de informatizado Unilog da empresa terceirizada responsável pela logística da Secretaria de Estado de Saúde do Pará (SESPA).

A identificação do tempo de espera no decorrer do processo de solicitação ao tratamento até a efetiva dispensação foi realizada por meio de análise dos Protocolos de Atendimento Eletrônicos (PAE) e do Sistema Unilog; ou seja, identificou-se as dificuldades dos utentes relacionadas ao acesso e tempo de espera para o recebimento dos medicamentos. Por conseguinte, foi analisado o tempo que o paciente esperou para receber o medicamento solicitado, tendo como início da contabilidade dos dias o período que compreende a data de entrada de seu processo até a data da primeira dispensação efetiva da tecnologia solicitada.

As planilhas de dispensações dos medicamentos nintedanibe e pirfenidona para os pacientes portadores de fibrose pulmonar idiopática, foram retiradas do Unilog pelo farmacêutico da farmácia de demandas da URE-DOCA. Os itens analisados englobaram o nome do paciente, o medicamento, tipo de demanda (administrativa ou judicial) e a data de atendimento/dispensação do medicamento solicitado.

\subsection{Análise dos dados e apresentação dos resultados}

Os dados foram plotados no programa Excel ( ${ }^{\circledR}$ 2016, analisados por meio de estatística descritiva e os dados apresentados quanto ao perfil socioeconômico de utentes com FPI no Estado do Pará, itinerário das dispensações de antifibróticos e os custos com aquisição de antifibróticos. Ressalta-se que o perfil socioeconômico abrange apenas as demandas administrativas; mas os dados de itinerário e de custos envolveram tanto as demandas administrativas e judiciais.

\subsection{Aspectos éticos}

Quanto aos aspectos éticos, registra-se que esta investigação foi submetida à Plataforma Brasil (SISNEP), conforme os termos da Resolução CNS n 466 de 12 de dezembro de 2012 (Brasil, 2012) e da Resolução CNS n ${ }^{\circ}$ 510, de 07 de abril de 2016 (Brasil, 2016); registrado via CAAE $n^{\circ}$ 95684918.6.0000.0018 e Parecer Consubstanciado $n^{\circ}$ 3.016.049. Os dados foram plotados no Excel® (2016).

\section{Resultados}

O presente estudo é inédito quanto a fornecer dados ainda não levantados por outros autores quanto ao perfil dos pacientes com fibrose pulmonar idiopática no Pará. Neste trabalho foram analisados os aspectos econômicos como renda; condições de moradia; município ou cidade de origem do paciente; faixa etária e sexo, além dos impactos financeiros para o estado do fornecimento destes medicamentos. Quanto aos aspectos socioeconômicos, as informações estão disponíveis apenas para os utentes atendidos através de demanda administrativa, visto que por demanda judicial não é obrigatória o preenchimento da ficha social.

\subsection{Perfil socioeconômico de utentes com FPI no Estado do Pará}

Recuperou-se os dados de 55 pacientes atendidos via demanda administrativa, os quais continham as fichas sociais para a análise. Quanto a renda dos pacientes atendidos via demanda administrativa (Tabela 1), observa-se que 83,63\% recebem de 1 a 4 salários-mínimos, caracterizando-os como de baixa renda. 
Tabela 1 - Renda dos pacientes atendidos via demanda administrativa.

\begin{tabular}{c|c|c}
\hline Renda & Frequência & Percentual \\
\hline 1 a 4 salários-mínimos & 46 & $83,63 \%$ \\
\hline 5 a 8 salários-mínimos & 3 & $5,45 \%$ \\
\hline 9 ou mais & 3 & $5,45 \%$ \\
\hline Sem renda & 1 & $1,81 \%$ \\
\hline Renda não informada & 2 & $3,63 \%$ \\
\hline Total & $\mathbf{5 5}$ & $\mathbf{1 0 0 \%}$ \\
\hline
\end{tabular}

Fonte: Itinerário de utentes com fibrose pulmonar idiopática usuários de nintedanibe e pirfenidona atendidos via judicial ou administrativa pela Secretaria de Estado de Saúde do Pará, 2020.

Quanto ao tipo de moradia dos pacientes atendidos via demanda administrativa (Tabela 2), foi achado que $90,90 \%$ residem em casa de alvenaria.

Tabela 2 - Tipo de moradia dos pacientes atendidos via demanda administrativa.

\begin{tabular}{c|c|c}
\hline Moradia & Frequência & Percentual \\
\hline Alvenaria & 50 & $90,90 \%$ \\
\hline Madeira & 03 & $5,45 \%$ \\
\hline Misto (alvenaria + madeira) & 02 & $3,63 \%$ \\
\hline Total & $\mathbf{5 5}$ & $\mathbf{1 0 0 \%}$ \\
\hline
\end{tabular}

Fonte: Itinerário de utentes com fibrose pulmonar idiopática usuários de nintedanibe e pirfenidona atendidos via judicial ou administrativa pela Secretaria de Estado de Saúde do Pará, 2020 .

Quanto ao número de moradores por domicílio de pacientes atendidos via demanda administrativa, observa-se que $61,81 \%$ residem com 1 a 3 pessoas.

Tabela 3 - Moradores por domicílio de pacientes atendidos via demanda administrativa.

\begin{tabular}{c|c|c}
\hline Número de moradores por domicílio & Frequência & Percentual \\
\hline 01 a 03 & 34 & $61,81 \%$ \\
\hline 04 a 06 & 16 & $29,09 \%$ \\
\hline 07 a 10 & 05 & $9,09 \%$ \\
\hline Total & $\mathbf{5 5}$ & $\mathbf{1 0 0 \%}$ \\
\hline
\end{tabular}

Fonte: Itinerário de utentes com fibrose pulmonar idiopática usuários de nintedanibe e pirfenidona atendidos via judicial ou administrativa pela Secretaria de Estado de Saúde do Pará, 2020.

Quanto ao tipo de moradia dos pacientes atendidos via demanda administrativa (Tabela 4), foi achado que $87,27 \%$ residem em casa própria. 
Research, Society and Development, v. 10, n. 16, e251101623936, 2021

(CC BY 4.0) | ISSN 2525-3409 | DOI: http://dx.doi.org/10.33448/rsd-v10i16.23936

Tabela 4 - Tipo de moradia dos pacientes atendidos via demanda administrativa.

\begin{tabular}{c|c|c}
\hline Moradia & Frequência & Percentual \\
\hline Alugada & 2 & $3,63 \%$ \\
\hline Cedida & 5 & $9,09 \%$ \\
\hline Própria & 48 & $87,27 \%$ \\
\hline Total & $\mathbf{5 5}$ & $\mathbf{1 0 0 \%}$ \\
\hline
\end{tabular}

Fonte: Itinerário de utentes com fibrose pulmonar idiopática usuários de nintedanibe e pirfenidona atendidos via judicial ou administrativa pela Secretaria de Estado de Saúde do Pará, 2020.

Quanto ao sexo, a ocorrência da Fibrose Pulmonar Idiopática em pacientes masculinos foi de 56,36\% e femininos de $43,63 \%$ (Tabela 5).

Tabela 5 - Ocorrência da Fibrose Pulmonar Idiopática em pacientes masculinos e femininos atendidos via demanda administrativa.

\begin{tabular}{|c|c|c|}
\hline Sexo & Frequência & Percentual \\
\hline Feminino & 24 & $43,63 \%$ \\
\hline Masculino & 31 & $56,36 \%$ \\
\hline Total & 55 & $100 \%$ \\
\hline
\end{tabular}

idiopática usuários de nintedanibe e pirfenidona atendidos via judicial ou administrativa pela Secretaria de Estado de Saúde do Pará, 2020.

Ao analisar a idade dos pacientes com Fibrose Pulmonar Idiopática atendidos pela Secretaria de Estado de Saúde do Pará (SESPA), nota-se que os valores variam, tendo um caso registrado em uma paciente com 30 anos de idade. Sabe-se, e as evidências encontradas na literatura confirmam, que a fibrose pulmonar idiopática acomete principalmente idosos acima dos 60 anos, mas isso não significa que a doença não ocorra em adultos com menos idade.

De acordo com o encontrado durante o levantamento e análise de dados, a maior ocorrência da fibrose pulmonar idiopática foi em pacientes entre 67 e 77 anos $(n=21)$ e a média de idade destes pacientes foi de 69,14 anos (Tabela 6). 
Research, Society and Development, v. 10, n. 16, e251101623936, 2021

(CC BY 4.0) | ISSN 2525-3409 | DOI: http://dx.doi.org/10.33448/rsd-v10i16.23936

Tabela 6 - Faixa etária dos pacientes portadores de Fibrose Pulmonar Idiopática.

\begin{tabular}{c|c}
\hline Faixa etária (anos) & $\mathbf{N}^{\circ}$ de pacientes \\
\hline 30 & 01 \\
\hline 31 a 44 & 04 \\
\hline 45 a 55 & 04 \\
\hline 56 a 66 & 10 \\
\hline 67 a 77 & 21 \\
\hline 78 a 88 & 12 \\
\hline 88 a 91 & 03 \\
\hline Total & $\mathbf{5 5}$ \\
\hline Média de idade & $\mathbf{6 9 , 1 4}$ anos \\
\hline
\end{tabular}

Fonte: Itinerário de utentes com fibrose pulmonar idiopática usuários de nintedanibe e pirfenidona atendidos via judicial ou administrativa pela Secretaria de Estado de Saúde do Pará, 2020.

Quanto ao município de origem dos pacientes, verificou-se que estes são predominantemente de Belém, capital do estado, com 55 pacientes (Figura 1).

Figura 1 - Município de origem dos pacientes atendidos via administrativa ou judicial.

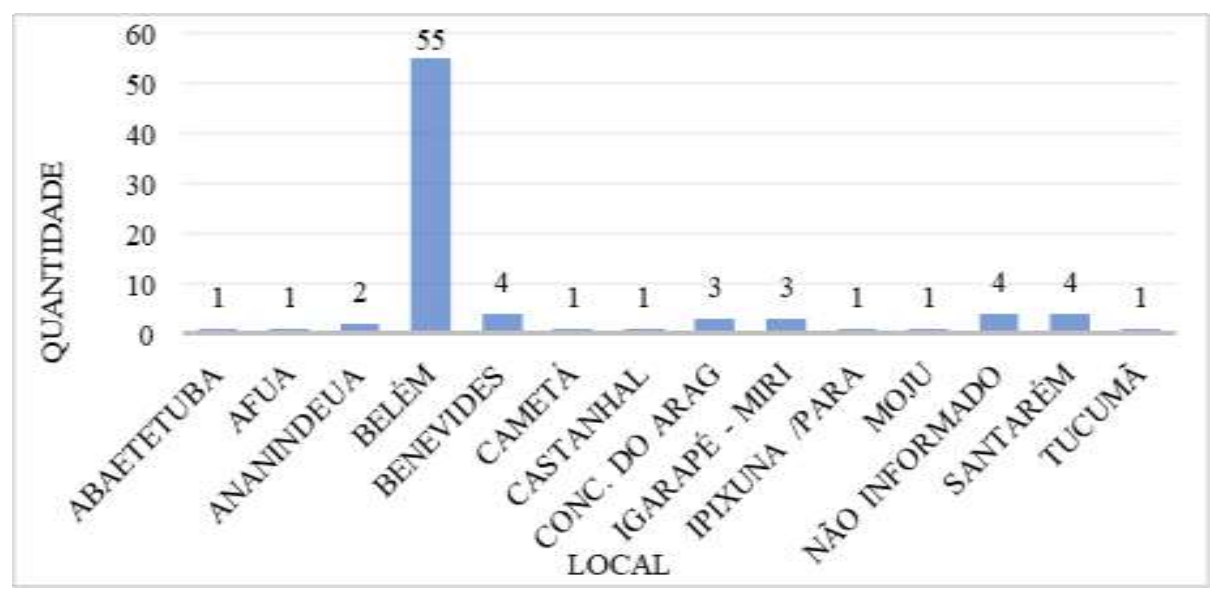

Fonte: Itinerário de utentes com fibrose pulmonar idiopática usuários de nintedanibe e pirfenidona atendidos via judicial ou administrativa pela Secretaria de Estado de Saúde do Pará, 2020.

\subsection{Itinerário das dispensações de antifibróticos}

Dos 81 pacientes, treze (13) evoluíram a óbito. Para investigar estes desfechos, foi necessário contactar as famílias dos pacientes, via telefone, que concordaram em fornecer informações sobre os casos. De acordo com os familiares, todos os pacientes faleceram em decorrência de serem portadores de fibrose pulmonar idiopática. Em 8 casos, os pacientes sequer tiveram a chance de iniciar o tratamento, pois não receberam o medicamento. Houve 1 caso em que o especialista (médico), recomendou descontinuar o tratamento devido o paciente estar convivendo com a ocorrência de efeitos adversos, efeitos estes que estavam superando o benefício do uso do medicamento antifibrótico.

O principal empecilho observado quanto a retarda o início do tratamento da fibrose pulmonar idiopática no estado do Pará é o acesso ao medicamento. Como já foi citado anteriormente, a aquisição é realizada por demanda individualizada; sendo assim, o paciente solicitante deve aguardar os procedimentos legais de licitação e compra serem efetivados para começar o tratamento. Inicialmente, seriam analisadas as dispensações dos medicamentos dos 81 pacientes, desde o ano de 2016 até 2019 , 
através dos relatórios de dispensação da UniHealth®, mas apenas 57 tinham registro de dispensações no sistema. Posteriormente, pôde-se perceber que o tempo de espera variou entre 0 dias até 285 dias e a média desde a solicitação do antifibrótico até a primeira dispensação ao paciente foi de 100,24 dias.

Ao investigar os processos dos pacientes que não receberam os medicamentos $(n=36)$ constatou-se que diversos deles já haviam sido adquiridos por meio de ordem bancária (OB), o que indica que foi realizada aquisição e o medicamento havia sido entregue na Central de Distribuição e estaria disponível para dispensação na farmácia da URE-Doca, mas o paciente não foi comunicado na maioria das vezes porque mudou o contato telefônico. Ou seja, um paciente que espera há vários meses para receber o medicamento e tem em seu processo a concluído, pode não o receber, por não saber que está disponível; observou-se deficiência na busca ativa desses produtos/processo que estão disponíveis, mas o interessado não é localizado. Por isso, observa-se que há tempos de espera curtos e outros bastante longos para o recebimento do medicamento (Tabela 7).

Tabela 7 - Tempo de espera desde a solicitação do antifibrótico até a dispensação.

\begin{tabular}{c|c|c|c|c}
\hline TEMPO DE ESPERA (dias) & ADMIMISTRATIVO & JUDICIAL & TOTAL & $\%$ \\
\hline 0 a 20 & 2 & 5 & 7 & $12,28 \%$ \\
\hline 21 a 49 & 10 & 4 & 14 & $24,56 \%$ \\
\hline 50 a 99 & 10 & 2 & 12 & $21,05 \%$ \\
\hline 100 a 130 & 5 & 4 & 9 & $15,78 \%$ \\
\hline 131 a 200 & 0 & 5 & 5 & $8,77 \%$ \\
\hline 201 a 239 & 6 & 2 & 8 & $14,03 \%$ \\
\hline 240 a 285 & 0 & 2 & 2 & $3,50 \%$ \\
\hline Total & 33 & 24 & 57 & $100 \%$ \\
\hline
\end{tabular}

Fonte: Itinerário de utentes com fibrose pulmonar idiopática usuários de nintedanibe e pirfenidona atendidos via judicial ou administrativa pela Secretaria de Estado de Saúde do Pará, 2020.

\subsection{Custos com aquisição de antifibróticos}

No estado do Pará, durante o período em que foi realizado o levantamento dos processos cadastrados no DEAF, entre os 81 pacientes que recebem os medicamentos para fibrose pulmonar idiopática, 40 recebem nintedanibe e 41 recebem pirfenidona. Entre os 40 que recebem nintedanibe, 16 solicitaram via judicial e 24 via administrativa. Se tratando da pirfenidona, entre os 41 pacientes, 7 solicitaram por via judicial e 34 pela via administrativa. Entre as 81 prescrições, 63 foram encaminhados por serviços públicos; 7 por serviços privados e 5 não informaram a origem da prescrição.

$\mathrm{Na}$ literatura não há uma imposição ou consenso em relação à qual medicamento deve ser prescrito, pois ambos se revelaram equivalentes quanto aos seus benefícios. A decisão sobre qual o paciente irá tomar depende do médico especialista.

Com base neste número de pacientes que haviam solicitado os medicamentos até o ano de 2019, e de acordo com dados de dispensação fornecidos pela Farmácia de Demandas Judiciais e Administrativas da empresa terceirizada UniHealth, buscou-se o custo unitário das cápsulas de nintedanibe e pirfenidona para calcular quanto custa o tratamento individual e o total.

Para a pirfenidona, o tratamento mensal de um paciente requer 270 cápsulas, de acordo com as recomendações da bula profissional do medicamento. Já o paciente que fará tratamento com nintedanibe necessita de 60 cápsulas ao mês (Tabela $8)$.

Para saber qual é o real custo do tratamento com Esbriet ${ }^{\circledR}$ o valor da aquisição das 270 cápsulas será multiplicado pelos 41 pacientes que recebem este medicamento. Tem-se, então, o impacto de aquisição de pirfenidona para o estado. Para a 
outra opção de antifibrótico, Ofev ${ }^{\circledR}$, o custo do tratamento será obtido pela multiplicação do custo para aquisição das 60 cápsulas pelos 40 pacientes que recebem esta tecnologia. Ressalta-se que mesmo o número de solicitantes de pirfenidona sendo maior que de nintedanibe, sua aquisição é feita por um custo significativamente menor (Tabela 8).

Tabela 8 - Custo unitário dos medicamentos nintedanibe e pirfenidona.

\begin{tabular}{cr|c}
\hline \multicolumn{2}{c|}{ Custo unitário (reais) } & \multicolumn{1}{c}{ Custo do tratamento por paciente/mês (reais) } \\
\hline Nintedanibe & $\mathrm{R} \$ 214,85$ & $\mathrm{R} \$ 12,891,10$ \\
\hline Pirfenidona & $\mathrm{R} \$ 28,02$ & $\mathrm{R} \$ 7,565,77$ \\
\hline
\end{tabular}

Fonte: Itinerário de utentes com fibrose pulmonar idiopática usuários de nintedanibe e pirfenidona atendidos via judicial ou administrativa pela Secretaria de Estado de Saúde do Pará, 2020.

O que se observou nos últimos anos, foi o crescimento nas prescrições para ambos, sendo a pirfenidona a mais prescrita. Apesar da pirfenidona ser a alternativa mais prescrita nos anos de 2017 e 2018, seu custo de aquisição ainda foi mais baixo do que o do nintedanibe. A principal dificuldade relacionada ao número de prescrições do Ofev ${ }^{\circledR}$, é o custo para o estado, visto que este é adquirido, por paciente, pela quantia de $\mathrm{R} \$ 12,891,10$ reais. Visando minimizar os impactos financeiros com a aquisição deste antifibrótico, a SESPA começou a recomendar que os prescritores solicitem a pirfenidona, que possui benefícios equivalentes aos do nintedanibe e é adquirida por um preço consideravelmente menor (Figura 2).

Com o aumento das solicitações dos medicamentos para fibrose pulmonar idiopática, há, consequentemente, o aumento dos custos com a sua aquisição. No ano de 2018 houve o maior investimento em antifibróticos pela SESPA e, apesar do nintedanibe ter sido menos prescrito (9) do que a pirfenidona (22), os gastos relacionados à sua aquisição foram maiores do que os gastos com a pirfenidona (Figura 3).

Figura 2 - Quantidade de processos atendidos pela Secretaria de Estado de Saúde do Pará ao longo dos anos de 2016, 2017, 2018 e 2019.

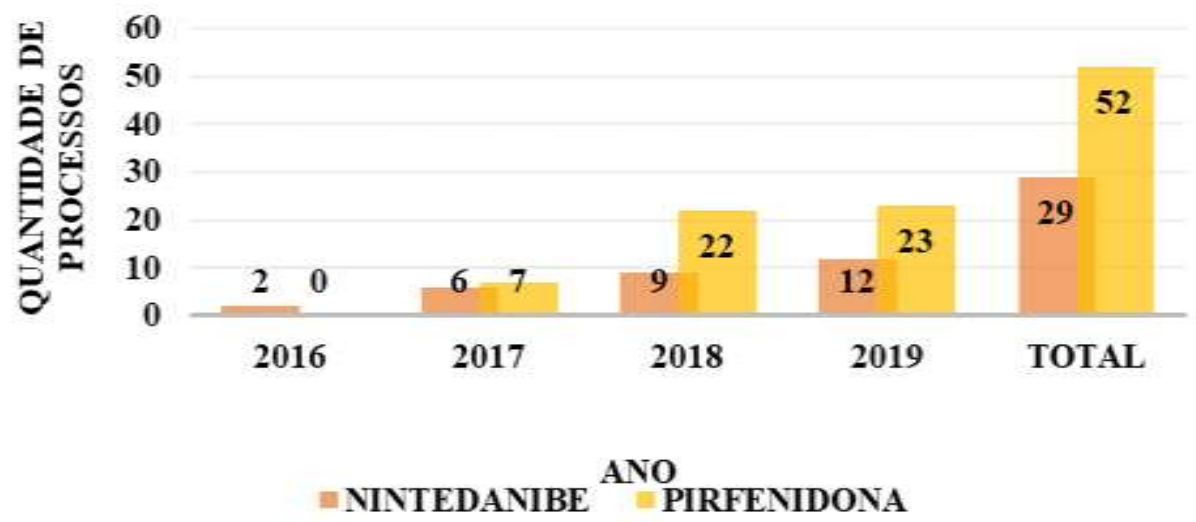

Fonte: Itinerário de utentes com fibrose pulmonar idiopática usuários de nintedanibe e pirfenidona atendidos via judicial ou administrativa pela Secretaria de Estado de Saúde do Pará, 2020. 
Figura 3 - Gastos do Departamento de Assistência Farmacêutica do Estado com a aquisição de antifibróticos.

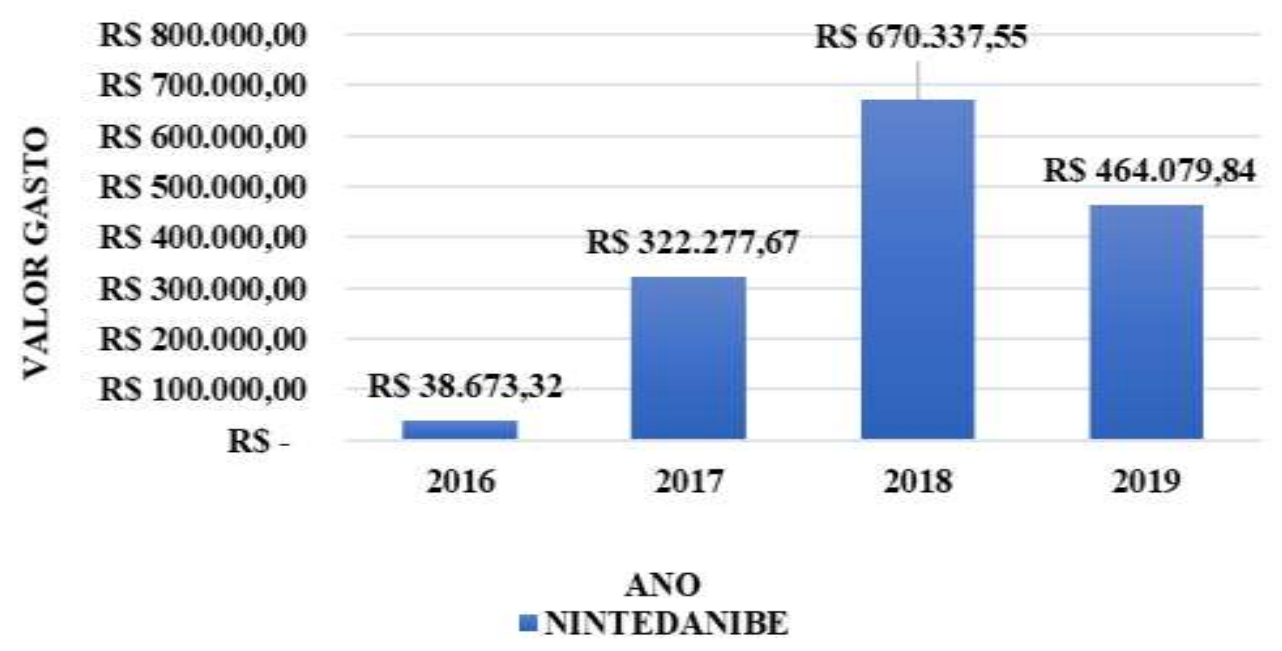

Fonte: Itinerário de utentes com fibrose pulmonar idiopática usuários de nintedanibe e pirfenidona atendidos via judicial ou administrativa pela Secretaria de Estado de Saúde do Pará, 2020.

\section{Discussão}

Avaliou-se, inicialmente, o perfil socioeconômico da amostra estudada por meio de análise dos processos via demanda administrativa, não sendo possível realizar a análise dos processos de pacientes via demanda judicial; pois, os mesmos, não realizam o preenchimento da ficha social, recomendação importante a ser feita à SESPA, para que o estado tenha o panorama completo dos pacientes que atende, o que possivelmente tornará as análises dos processos mais completas e fidedignas.

$\mathrm{Na}$ amostra em questão, foi possível encontrar um desequilíbrio entre o sexo masculino $(\mathrm{n}=31)$ em relação ao sexo feminino ( $\mathrm{n}=24)$, obtendo-se uma predominância masculina ( $\mathrm{n}=56,36 \%)$, corroborando com Raghu et al., (2006) que descreve uma maior prevalência da doença em homens em relação a mulheres. Este resultado pode ser comparado aos dados da literatura, onde Lee (2018) cita a proporção de ocorrência de 2 casos em homens para 1 caso em mulheres.

Constatou-se, também, que a idade dos pacientes acometidos pela fibrose pulmonar idiopática variou de 30 a 91 anos, onde, o maior número de casos foi em pacientes entre 67 a 77 anos $(\mathrm{n}=21)$, se obtendo uma média de idade de 69,14. Os resultados obtidos assemelham-se aos de Swigris e Brown (2006) os quais comprovaram em seu estudo que a fibrose pulmonar idiopática aumenta sua prevalência vertiginosamente em pacientes com idade igual ou superior a 75 anos.

Um resultado atípico, demonstrou um paciente de 30 anos portador de fibrose pulmonar idiopática, achado este, que se torna discrepante da gama de resultados descritos na literatura. Raghu et al., (2006) descreve que, ao coletar informações de uma ampla base de dados dos Estados Unidos da América, a incidência da fibrose pulmonar idiopática em pessoas entre 18 e 34 anos encontrada estava entre 0,4 e 1,2 casos por 100.000 pessoa/ano. Entretanto, quando se avaliou a incidência estimada da fibrose pulmonar idiopática em pessoas com 75 anos de idade ou mais, os resultados foram notavelmente mais altos e variaram de 27,1 a 76,4 casos por 100.000 pessoa/ano. Deste modo, constata-se que a Fibrose Pulmonar Idiopática possui índices maiores em pacientes idosos (Baddini-Martinez \& Pereira, 2015).

01 paciente descontinuou o tratamento com medicamento antifibrótico em decorrências de apresentar reações adversas gastrointestinais severas, onde o benefício do uso do medicamento não estava sendo superior aos danos ocasionados ao paciente. Bargagli et al., (2019) registraram que as reações gastrointestinais são as mais frequentes, e diversas vezes sendo responsável pelo abandono do tratamento medicamento para fibrose pulmonar idiopática. Dentre os efeitos adversos 
relacionados ao tratamento com medicamentos antifibróticos, os eventos relacionados ao trato gastrointestinal apresentam-se predominantes, tendo destaque a nomeada diarreia (Pereira et al., 2019).

$\mathrm{Na}$ Tabela 1, encontra-se explanado a renda familiar dos pacientes. 83,63\% recebem de 1 a 4 salários-mínimos, sendo esta quantia considerada baixa, quando se leva em consideração o alto custo dos medicamentos, não sendo suficiente para custear sequer 1 mês de tratamento do antifibrótico mais “barato”, pirfenidona, que custa R\$7,565,77 reais. É possível inferir que mesmo os pacientes que possuem uma renda "privilegiada", não conseguem adquirir os medicamentos pelos seus próprios recursos financeiros, levando em consideração o custo oneroso das tecnologias utilizadas.

Quanto ao tipo de moradia (Tabela 2), tem-se que, 50 utentes $(90,90 \%)$ residem em casas de alvenaria, porém, não foi possível avaliar as condições reais do local, apenas o tipo de construção. Ao avaliar-se em que condições esses utentes residem, observou-se que $87,27 \%$ dos pacientes possuem casa própria. Não foi encontrado literaturas disponíveis que possam correlacionar com os achados deste estudo.

Quando avaliado quantos moradores residem em seus domicílios, a maior parte reside juntamente com 01 a 03 pessoas, equivalendo a $61,81 \%$. Este fato pode ser considerado um ponto positivo para o tratamento dos pacientes, tendo em vista, que em sua maioria são idosos e muitas vezes não gozam de plenas capacidades físicas. Portanto, o auxílio de terceiros se mostraria benéfico para o tratamento dos utentes (Tabela 3).

Quanto ao município de origem dos utentes, constatou-se que 55 pacientes são de Belém, Pará, sendo este o município onde mais se concentra portadores de fibrose pulmonar idiopática no estado do Pará (Figura 1). Realizou-se a busca por estudos científicos sobre o mesmo, porém, não foi encontrado nenhuma literatura nas bases de dados que pudessem corroborar com os achados, sendo assim, este, o primeiro estudo abordando o quesito município em relação a utentes portadores de Fibrose Pulmonar Idiopática no estado do Pará.

Ao avaliar-se o tempo de espera dos pacientes para o recebimento dos medicamentos, encontrou-se que o tempo compreendido em dias, foi de 0 a 285. Ao analisar o tempo de espera dos pacientes por tipo de demanda, chama a atenção que os de demanda judicial nem sempre são os mais beneficiados, em que pese 05 pacientes ter recebido em até 20 dias, os demais aguardaram mais de dois meses para receber, sendo que dois pacientes tiveram a primeira dispensação após 240 a 285 dias do recebimento da ação pela secretaria para cumprimento da ação judicial. A demora no recebimento do medicamento pode implicar em problemas ao usuário, que precisa dar início ao seu tratamento rapidamente, pois uma das principais complicações da doença é a expectativa de vida de 2 a 5 anos após ser confirmado o diagnóstico (Raghu et al., 2011), e nos processos e documentos entregues ao DEAF não se tem informações sobre quão avançada a doença está nos diferentes pacientes atendidos, por isso, é recomendado que o tempo de espera seja o menor possível.

Observou-se que o custo unitário e mensal dos medicamentos antifibróticos nintedanibe e pirfenidona por paciente é muito elevado. Para nintedanibe o valor unitário da cápsula é de $\mathrm{R} \$ 214$, 85; e o valor mensal é de R\$12,891,10. Para o medicamento pirfenidona, o valor unitário custa um total de $\mathrm{R} \$ 28,02$ e o valor mensal R $\$ 7,565,77$ (Tabela 8).

Considerando a quantia total destinada à aquisição dos medicamentos analisados nesta pesquisa, acredita-se que a mesma tenha repercutido sobre o orçamento destinado à assistência farmacêutica no Estado do Pará, pois Laffin et al (2017) afirma: [...] um desembolso dos estados, municípios e União de 7 bilhões de reais para arcar com demandas judiciais na área da saúde, um pouco mais de $5 \%$ do orçamento total da saúde [...]. As demandas em excesso comprometem todo o clico da assistência farmacêutica ao ter que lidar com uma exigência de medicamentos que não faz parte do seu planejamento, e a rapidez nesse processo impede que o gestor siga os trâmites legais da administração pública, impactando nos aspectos administrativos e orçamentários (Pepe et al. 2010). 
É válido considerar que tais demandas têm o efeito positivo de garantir o acesso em situações especiais que comprometem a qualidade de vidas em idosos, como a da FPI, ainda mais quando há atraso na incorporação de medicamento, em contrapartida, podem gerar efeitos negativos, sendo estes: comprometimento dos princípios do SUS; dificuldades na gestão da AF; uso não racional de medicamentos (Pepe et al. 2010).

O estado, visando seguir os princípios e diretrizes do SUS, está realizando a aquisição destes medicamentos, ainda que eles não sejam incluídos em PCDTs e nem tenham sido incorporados ao SUS pela CONITEC. A discussão sobre fornecer medicamentos de alto custo não incluídos ao SUS vem à tona com grandes debates acerca das aquisições de opções terapêuticas inovadoras, principalmente porque este é um impacto orçamentário não previsto pelo gestor.

Esta questão gera controvérsia pois são gastos altos, não programados e que, tratando-se de doenças raras, tendem a beneficiar poucas pessoas; e também porque em alguns casos os medicamentos carecem de dados sobre eficácia, segurança e qualidade, por serem inovadores e recém-lançados no mercado, podendo até afetar a saúde dos pacientes ao invés de ajudá-los. Neste contexto, a SESPA regulamentou esse acesso através da IN 01/17, mas observamos que há necessidade de ter uma Câmara Técnica de especialistas para avaliar quais são os pacientes que teriam prioridade de atendimento e o monitoramento contínuo, justamente por se tratar de destinação de recurso orçamentário muito elevado.

A via administrativa é uma das novas institucionalidades criadas como alternativa às demandas judiciais para amenizar a problemática da garantia do acesso ao medicamento pelo sistema público de saúde brasileiro. Apesar apresentar-se como uma das novas institucionalidades criadas como alternativa para as demandas judiciais, foi possível identificar a existência de lacunas na compreensão dos déficits assistenciais, assim como no empoderamento dos usuários quanto ao direito ao acesso ao medicamento garantido constitucionalmente. Diante do exposto, é preciso considerar a necessidade de aprimoramento dos protocolos de acesso aos medicamentos pela via administrativa como mecanismo de efetivação do acesso ao medicamento, e não somente como uma via que evita uma decisão judicial (Provin, 2014).

Ho et al., (2017) discutiram a relação custo-efetividade dos antifibróticos, concluindo que os custos totais de pirfenidona e de nintedanibe foram $\mathrm{R} \$ 319.689$ e $\mathrm{R} \$ 522.887$, respectivamente. Já os anos de vida salvos resultantes foram 6,536 para pirfenidona e 5,726 para nintedanibe, resultando em um valor incremental de 0,810. E, a partir dos valores incrementais de custos e efetividade, a pirfenidona demonstrou ser uma opção terapêutica dominante quando comparada ao nintedanibe.

Dificuldades, limitações e viés: Dificuldades em ter acesso aos utentes; visto que, nem todos os telefones que constavam nos processos estavam atualizados. Quanto aos processos judiciais não foi possível ter acesso a ficha social de todos os utentes; visto que, os pacientes provenientes de demanda judicial não realizam o preenchimento da ficha social, pois como há uma liminar com prazo para cumprimento, encaminha-se diretamente para aquisição o processo oriundo do Tribunal de Justiça e não passa pelo setor das Assistentes Sociais - Assessoria Especial da SESPA. Limitações de acesso dos utentes aos medicamentos, pois quando contactados não tinham conhecimento que seus medicamentos já estavam disponíveis; portanto, dificultando o tratamento farmacológico. Quanto aos potenciais vieses, pode-se inferir que o tipo de amostragem e as vias de comunicação podem ter influenciados nos resultados.

Contribuição do estudo: Torna-se conhecido o perfil socioeconômico, epidemiológico e o itinerário de utentes portadores de Fibrose Pulmonar Idiopática, os quais recebem os medicamentos antifibróticos nintedanibe e pirfenidona via demanda administrativa ou judicial, na farmácia de demandas judiciais e administrativas da Secretaria de Estado de Saúde do Pará. 


\section{Conclusão}

O estudo possibilitou conhecer as complexidades de acesso ao tratamento envolvendo os antifibróticos. A SESPA ao institucionalizar o acesso dos antifibróticos através de demanda administrativa, buscou otimizar os custos e qualificar a demanda, mas a estratégia adotada pela instituição necessita ser aprimorada, com vistas para a construção de políticas mais efetivas como adoção dos protocolos de acesso aos medicamentos e diálogo permanente com o judiciário a fim de possibilitar sua sustentabilidade.

Somente com uma ampla coalizão de esforços, envolvendo cientistas básicos, pesquisadores clínicos, médicos, farmacêuticos, operadores do direito, empresas farmacêuticas, associações representativas de pacientes e familiares e com o apoio governamental, poderá ser garantido acesso ao tratamento para a melhoria da qualidade de vida dos pacientes vivendo com FPI e fortalecimento da Política de Doenças Raras no estado do Pará.

A partir dos achados, pode-se inferir que há predominância de pacientes do sexo masculino, com idade entre 67 e 77 anos, provenientes do município de Belém-Pará, residentes em moradia própria, em sua maioria construída de alvenaria, contando com 1 a 3 moradores em suas residências, com uma renda familiar variando entre 1 e 4 salários mínimos.

Há uma prevalência de demanda via administrativa em relação a demanda via judicial. Todos os utentes cumprem com os critérios de inclusão. Contudo, os pacientes têm dificuldade para efetuar a renovação do processo de aquisição de medicamento; logo, prejudicando a continuidade do tratamento.

O tempo de espera para recebimento do medicamento é longo, o que pode prejudicar a qualidade e sobrevida dos utentes. Observa-se altos gastos com a aquisição dos medicamentos antifibróticos, sendo estes gastos não previstos pelo gestor; não orçados.

Recomenda-se o aprimoramento do processo de cadastro dos utentes quanto a dados e informações por meio da ficha social, preferencialmente por meio informatizado, possibilitando melhor acesso a informações socioeconômicas e sociodemográficos, além de composição de Câmara Técnica de especialista (pneumologistas) para realizar avaliação que urgência de atendimentos e monitoramento da terapia. Também, a implementação de estratégias do cuidado farmacêutico, entre elas, a melhoria do processo de comunicação efetiva entre utentes e farmacêuticos, agilizando o acesso e o uso com qualidade dos medicamentos antifibróticos. Estudos futuros sobre a equidade ou análise de subgrupos precisam ser realizados.

\section{Referências}

American Thoracic Society. (2000). Idiopathic Pulmonary Fibrosis: Diagnosis and Treatment International Consensus Statement. Am J Respir Crit Care Med. 161:646-664. https://doi.org/10.1164/ajrccm.161.2.ats3-00

Baddini-Martinez, J., \& Pereira, C. A. (2015). How many patients with idiopathic pulmonary fibrosis are there in Brazil? J Bras Pneumol. 41(6):560-561. $10.1590 /$ S1806-37562015000000165

Baddini-Martinez, J., Baldi, B. G., Costa, C. H., Jezler, S., Lima, M. S., \& Rufino, R. (2015). Update on diagnosis and treatment of idiopathic pulmonary fibrosis. J Bras Pneumol. 41(5):454-466. ISSN 1806-3713.

Bargagli, E., Piccioli, C., Rosi, E., Torricelli, E., Turi, L., Piccioli, E., Pistolesi, M., Ferrari, K., \& Voltolini, L. (2019). Pirfenidone and Nintedanib in idiopathic pulmonary fibrosis: Real-life experience in an Italian referral center. Pulmonology. 25(3):149-153. https://doi.org/10.1016/j.pulmoe.2018.06.003

Brandão, Y. H. C., Bormann, P. D. S., Queiroz, A. N., \& Soler, O. (2021). Cumprimento do protocolo clínico para atendimento de usuários de análogos de insulina em portadores de Diabetes Mellitus via judicial em Belém, Pará. Research, Society and Development. 10(1):e31310111800. ISSN 2525-3409. http://dx.doi.org/10.33448/rsd-v10i1.117800

Brasil. Conselho Nacional de Saúde. Resolução CNS n 510, de 07 de abril de 2016. Dispõe sobre as normas aplicáveis a pesquisas em Ciências Humanas e Sociais cujos procedimentos metodológicos envolvam a utilização de dados diretamente obtidos com os participantes ou de informações identificáveis ou que possam acarretar riscos maiores o que os existentes na vida cotidiana. Brasília. Distrito Federal.

Brasil. Conselho Nacional de Saúde. Resolução CNS no 466 de 12 de dezembro de 2012. Aprova as diretrizes e normas regulamentadoras de pesquisas envolvendo seres humanos. Brasília. Distrito Federal. 
Brasil. Ministério da Saúde. Relatório de Recomendação para priorização de Protocolo Clínico e Diretrizes Terapêuticas para Atenção Integral às Pessoas com Doenças Raras. nº 142, maio/2015. Home Page: www.conitec.gov.br

Cannon, L. R. C. (2012). Ações judiciais impetradas para obtenção de medicamentos e tratamentos especiais: a judicialização da saúde. Revista Brasília Médica. [Internet]. 49(3). http://netamaria.com.br/testes/ambr/2013/03/05/acoes-judiciais-impetradas-para-obtencao-de-medicamentos-e-tratamentosespeciais-a-judicializacao-da-saude/.

Catanheide, I. D., Lisboa, E. S., \& Souza, L. E. P. F. (2016). Características da judicialização do acesso a medicamentos no Brasil: uma revisão sistemática. PHYSIS/Rio de Janeiro. 26(4):1335-1356. https://doi.org/10.1590/s0103-73312016000400014.

Ho, R. S., Rufino, C. S., Lisondo, C. M., \& Alves, M. R. D. (2017). Cost-Effectiveness Analysis of Pirfenidone Versus Nintedanib on The Treatment of Idiopathic Pulmonary Fibrosis. Value in Health. 20(9):A893-A894. https://doi.org/10.1016/j.jval.2017.08.2695.

Ho, R. S., Rufino, C. S., Oliveira, C. S. K. S., Lisondo, C. M., \& Alves, M. R. D. (2017). Análise de custo-efetividade de pirfenidona em comparação a nintedanibe no tratamento de fibrose pulmonar idiopática na perspectiva do sistema suplementar de saúde brasileiro. J. bras. econ. Saúde. 9(1). 10.21115/JBES.v9.suppl1.89-95

Instituto Brasileiro de Geografia e Estatística. (2015). Censo 2010. Distribuição da população por sexo, segundo os grupos de idade. http://censo2010.ibge.gov.br/sinopse/ webservice/frm_piramide.php Acesso em: 21/11/2019.

Kaminosono, A. N., Gomes, J. S., \& Soler, O. (2020). Perfil da qualidade de vida em utentes idosos com Fibrose Pulmonar Idiopática no Estado do Pará. Braz. J. Heal. Rev. 3(5):14123-14134. ISSN 2595-6825. https://doi.org/10.34119/bjhrv3n5-218

Kaminosono, A. N., Sousa, E. K. S., Gillet, A. M. F., \& Soler, O. (2020). Overview de revisões sistemática e avaliação econômica de antifibróticos (nintedanib e pirfenidona) no tratamento da Fibrose Pulmonar Idiopática - FPI. Braz. J. of Develop. 6(10):76258-76274, ISSN 2525-8761. 10.34117 / bjdv6n10-158

Laffin, H. F., \& Bonacim, C. A. G. (2017). Custos da saúde: judicialização de medicamentos ofertados pelo SUS. In: Anais do XXIV Congresso Brasileiro de Custos de Florianópolis. 15 a 17 de novembro de 2017. Florianópolis. Santa Catarina.

Lee, J. (2018). Fibrose Pulmonar Idiopática. Manual MDS: Versão para profissionais de saúde. University of Colorado. Denver. USA. https://www.msdmanuals.com/pt-br/profissional/dist\%C3\%BArbios-pulmonares/doen\%C3\%A7as-pulmonares-intersticiais/fibrose-pulmonaridiop $\%$ C3\%A1tica

Loveman, E., Copley, V. R., Scott, D. A., Colquitt, J. L., Clegg, A. J., \& O’Reilly, K. M. A. (2015). Comparing new treatments for idiopathic pulmonary fibrosis - a network meta-analysis. BMC Pulm Med. 15(1):37. https://doi.org/10.1186/s12890-015-0034-y.

Maher, T. M., \& Strek, M. E. (2019). Antifibrotic therapy for idiopathic pulmonary fibrosis: time to treat. Respir Res. 20(1):1-9. https://doi.org/10.1186/s12931-019-1161-4

Minayo, M. C. S. (2012). Análise qualitativa: teoria, passos e fidedignidade. Cien Saude Colet. 17(3):621-626. https://doi.org/10.1590/S141381232012000300007

Morais, A. (2019). Idiopathic pulmonary fibrosis: accurate diagnosis and early treatment. J. bras. pneumol. 45(5):e20190353. https://doi.org/10.1590/1806$3713 / \mathrm{e} 20190353$

Mota, D. M., Fernandes, M. E. P., \& Coelho, H. L. L. (2003). Farmacoeconomia: um Instrumento de Eficiência para a Política de Medicamentos do Brasil. Revista Acta Farmacêutica Bonaerense. 22(2):177-86. ISSN: 0326-2383.

Naqvi, M., \& West, A. (2019). Diagnosis and management of idiopathic pulmonary fibrosis. Clin Pharm. 10.1211/CP.2019.20206233.

Pepe, V. L. E., Figueiredo, T. A., Simas, L., Castro, O. C. G., \& Ventura, M. (2010). A judicialização da saúde e os novos desafios da gestão da assistência farmacêutica. Ciência e Saúde Coletiva. 15(5):2405-14. http://dx.doi.org/10.1590/51413-81232010000500015.

Pereira, C. A. C., Baddini-Martinez, J. A., Baldi, B. G., Jezler, S. F. O., Rubin, A. S., Alves, R. L. R. A., Zonzin, G. A., Quaresma, M., Trampisch, M., \& Rabahi, M. F. (2019). Segurança e tolerabilidade de Nintedanibe em pacientes com fibrose pulmonar idiopática no Brasil. J Bras Pneumol. 45(5). https://doi.org/10.1590/1806-3713/e20180414

Provin, M. (2014). The perceptions of users of medicines about the access to them by administrative requests. https://doi.org/10.1590/S010181082006000100005

Raghu, G., Collard, H. R., Egan, J. J., Martinez, F. J., Behr, J., Brown, K. K., Colby, T. V., Cordier, J-F., Flaherty, K. R., Lasky, J. A., \& Lynch, D. A. (2011). An official ATS/ERS/JRS/ALAT statement: idiopathic pulmonary fibrosis: evidence-based guidelines for diagnosis and management. Am $J$ Respir Crit Care Med. 183(6):788-824. 10.1164/rccm.2009-040GL

Raghu, G., Weycker, D., Edelsberg, J., Bradford, W. Z., \& Oster, G. (2006). Incidence and prevalence of idiopathic pulmonary fibrosis. Am J Respir Crit Care Med. 174(7):810-816. 10.1164/rccm.200602-163OC

Ren, H., Wang, K., Yang, H., \& Gao, L. (2017). Efficacy and adverse events of pirfenidone in treating idiopathic pulmonary fibrosis. Saudi Medical Journal. 38(9): 889. 10.15537/smj.2017.9.19349

Richeldi, L., Baldi, F., Pasciuto, G., Macagno, F., \& Panico, L. (2019). Current and future idiopathic pulmonary fibrosis therapy. The Am. J. Med. Sci. 357(5):370-373. 10.1016/j.amjms.2019.02.006 
Research, Society and Development, v. 10, n. 16, e251101623936, 2021

(CC BY 4.0) | ISSN 2525-3409 | DOI: http://dx.doi.org/10.33448/rsd-v10i16.23936

Robalo-Cordeiro, C., Campos, P., Carvalho, L., Campainha, S., Clemente, S., Figueiredo, L., Jesus, J. M., Marques, A., Souto-Moura, C., Pinto Basto, R., Ribeiro, A., Serrado, M., \& Morais, A. (2016). Consensus document for the diagnosis and treatment of idiopathic pulmonary fibrosis: Joint Consensus of Sociedade Portuguesa de Pneumologia, Sociedade Portuguesa de Radiologia e Medicina Nuclear e Sociedade Portuguesa de Anatomia Patológica. Revista portuguesa de pneumologia, 22(2):112-122. https://doi.org/10.1016/j.rppnen.2016.01.003.

Rogliani, P., Calzetta, L., Cavalli, F., Matera, M. G., \& Cazzola, M. (2016). Pirfenidone, nintedanib and N-acetylcysteine for the treatment of idiopathic pulmonary fibrosis: A systematic review and meta-analysis. Pulm Pharmacol Ther. 40, 95-103,. https://doi.org/10.1016/j.pupt.2016.07.009

Rufino, R. L., Costa, C. H. D., Accar, J., Torres, G. R., Silva, V. L., Barros, N. P., \& Graça, N. P. (2013). Incidence and mortality of interstitial pulmonary fibrosis in Brazil. Interstitial lung disease: epidemiology, evaluation and pathogenesis. Am Thorac Soc,. A1458-A1458. Incidence And Mortality Of Interstitial Pulmonary Fibrosis In Brazil | A42. INTERSTITIAL LUNG DISEASE: EPIDEMIOLOGY, EVALUATION AND PATHOGENESIS (atsjournals.org)

Sociedade Brasileira de Pneumologia e Tisiologia. (2012). Diretrizes de Doenças Pulmonares Intersticiais da Sociedade Brasileira de PNeumologia E Tisiologia. J Bras Pneumol. 38(S2): S1-S133.

Swigris, J. J., \& Brown, K. K. (2006). Fibrose pulmonar idiopática: uma década de progressos. J Bras Pneumol. 32(3):249-260. https://doi.org/10.1590/S180637132006000300012

Ventura, M., Simas, L., Pepe, V. L. E., \& Schramm, F. R. (2010). Judicialização da saúde, acesso à justiça e a efetividade do direito à saúde. PHYSIS/Rio de Janeiro. 20(1):77-100. https://doi.org/10.1590/S0103-73312010000100006.

Victora, C. G., Barreto, M. L., Leal, M. C., Monteiro, C. A., Schmidt, M. I., Paim, J. et al. (2011). Condições de saúde e inovações nas políticas de saúde no Brasil: o caminho a percorrer. The Lancet. Série Saúde no Brasil. (1):90-102. http://download.thelancet.com/flatcontentassets/pdfs/brazil/brazilpor6.pdf

Yin, R. K. (2015). Estudo de caso: planejamento e métodos. (5a ed.), Bookman. 